\title{
The Effect of Teacher Attitudes on Students' English Reading Proficiency
}

\section{OPEN ACCESS}

Manuscript ID:

ENG-2020-08043387

Volume: 8

Issue: 4

Month: September

Year: 2020

P-ISSN: 2320-2645

E-ISSN: 2582-3531

Received: 10.06.2020

Accepted: 27.08.2020

Published: 01.09.2020

\section{Citation:}

Ahmad, Zakia. "The Effect of Teacher Attitudes on Students' English Reading Proficiency." Shanlax International Journal of English, vol. 8, no. 4, 2020, pp. 25-34.

DOI: https://doi.org/10.34293/ english.v8i4.3387

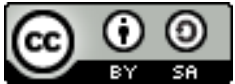

This work is licensed under a Creative Commons Attribution-ShareAlike 4.0 International License

\section{Zakia Ahmad}

Associate Professor, Department of English, University of Asia Pacific, Dhaka, Bangladesh https://orcid.org/0000-0002-3387-5706

\begin{abstract}
One of the most important language skills of a literate person is the skill to read. Reading means 'reading and understanding' (Ur, 1999). Students in Bangladesh go through a long process of education but still do not attain this skill proficiently; even at the secondary level of education they are unaware of the importance of reading. The English reading proficiency of students is dependent on the instruction they receive. Students do not realize that comprehension is the most important part of reading. The relationship between education and language is interdependent and failure to acquire language skills leads to failure in education. This study has focused on the attitude of teachers towards teaching English reading, how it affects their mode of instruction and how in turn this affects the reading proficiency of students. Analysis of results revealed that negative teacher attitude towards reading produces low proficiency readers of English. Research was carried out on both teachers and students. The results have shown that neither the students nor the teachers are aware of the reading strategies or sub-skills that they are required to employ while reading. Students do not know how to approach their reading materials, nor do they apply the reading strategies necessary for comprehension. The study has shown that the teachers themselves are not aware of these strategies and thus they cannot apply them to their teaching.
\end{abstract}

Keywords: Reading skills, Proficiency, Strategies, Schema, Comprehension and Attitude

\section{Introduction}

This paper studied the effect of teacher attitudes on students' English reading proficiency. The area of research was to test whether teacher attitudes towards reading effects the reading proficiency of students. Reading, as defined in the Oxford companion of the English Language, is the process of extracting meaning from written or printed language, it is one of the four language skills (listening, speaking, reading and writing) and one of the two key aspects of literacy (reading and writing).We read for various purposes and gather meaning. In all types of reading, comprehension which is a cognitive skill is essential (Walter, 2007 cited in McKee, 2012). Comprehension is the ability of readers to construct meaning from a piece of written text. Comprehension instruction should be an integral part of beginning reading instruction. The stages of reading can be illustrated as follows:

- First, the symbols and letters have to be perceived and then decoded.

- Second, we have to understand the words to understand the text.

- Third, from this understanding we gather meaning from the text.

Experts have defined reading in various ways. Gray (1950) has shown reading to be a four-step process

- Perception of the word.

- Comprehension of its meaning.

- Reaction of the meaning in terms of prior knowledge.

- Integration of the idea into one's background of experience. 
Being able to decode letters and symbols does not signify reading. Neither does pronouncing the words aloud. The more incomprehensible the text is, the longer it takes to read it. Reading a second/ foreign language is a difficult task. Teachers have to be aware of these factors as they proceed in their instructions. Reading is an essential skill that people need to acquire for being successful in life (McKee, 2012). The schema theory states that our comprehension depends on our knowledge of the world which is provided by the experiences that we have of this world. Schema is a concept through which we can interpret texts (Nuttal, 1996). The text might pose a problem for readers who do not have the relevant schema. If the reader does not have the schema at all or if it is different from the writer's then comprehension will be impossible. It is the task of the teacher to provide the students with the relevant schemata and prepare them for their reading tasks. In some instances the teachers themselves do not have the relevant schema to comprehend English texts based on an English culture.

In Bangladesh English is the only foreign language being studied in the curriculum and it is a compulsory component of the syllabus at all levels of schooling. However, low contact situation with the language, poor curriculum, hastily made short term education policies have made the teaching of English very difficult in Bangladesh. On one side there is the policy of discarding English and on the other an attempt to improve it. In the Foreword of the Education Policy 2010, although the need for language, mathematics, history, science education is mentioned, there is no specific mention of English as such. The situation of English language teaching has become highly paradoxical. Despite a literacy rate of $72.8 \%$ percent at present (Human Development Report, 2017), an even lesser percent know a foreign or second language like English.

Secondary Examinations Board records show ninety percent of the failure in the public exams occurs due to failure in English. Research has shown that students lack the English language proficiency required for their higher studies. The percentage of pass in English at the SSC exams in 2007 was 86\% and in 2008 this came down to $76 \%$ (Sharifuzzaman, 2009). There is a positive relationship between language and education and every educational failure of an individual is due to some kind of failure in language (Srivastava, 1995). One of the reasons for failure at schools is the low reading proficiency of students. Students who have difficulties in reading choose neither to read nor to engage in other tasks involving reading (Stanovich, 1980), so reading difficulties create reluctant readers. For effective teaching of reading to take place, teachers have to address the problems students face in reading comprehension and use specific methods for teaching reading (Ganie, Deliana and Rangkuti, 2019).

The target level chosen for this research study was the Secondary School level, classes IX and X specifically. It is at the secondary level (between the ages of 14 and 17 when reading can be independent and complex) that the basic principles need to be ingrained in students. Students need to be proficient in their language skills as they go from the secondary level to higher levels of education, otherwise low reading proficiency may hinder their higher education. Khatun and Begum (2000) have found that students score the lowest in English in the two public exams (S.S.C. and H.S.C.). When the Communicative Language Teaching (CLT) approach was introduced in Bangladesh in the 1990s some major changes were brought about into the curriculum. A new English textbook English for Today (EFT) was introduced at the secondary and higher secondary level. However, it had to go through several stages of revisions (Rahman, 2015). Changes were made in language, methodology and content. The Teacher's Guide to English for Today is supposed to be supplied by the National Curriculum and Text Book Board (NCTB) to all the schools of the country. But none of the schools which were taken as samples had a copy of the book. The Teacher's Guide provides a guideline for teachers, with the help of the Guide teachers could make their teaching effective.

The objective of this study was to verify whether teacher attitudes are responsible for low reading proficiency of students. In order to achieve the objective of this study, it was necessary to understand whether there was a relationship between teachers' attitudes and low proficiency readers of English. The study was guided by the following research 
question: Is teacher attitude towards reading related to students' English reading proficiency? In order to answer this research question, a mixed methods approach was used to elicit data from 100 students and 8 English teachers from the secondary school level. Data collection was conducted in both English and Bangla Medium schools in Dhaka, the capital city of Bangladesh. Both teachers and students of the same classes from each school were chosen for the study.

\section{Review of Literature}

Nuttal(1996) contends that a reading development program should ensure that students should be able to read authentic texts in a foreign language at an appropriate speed with good comprehension and feel comfortable about it. According to this view the teacher's responsibilities become manifold. Some of these responsibilities are to prepare tasks appropriate for students, see that the students enjoy their tasks, to help students develop their skills, to encourage reading through discussion and scaffolding (Wood, 2005 ) and also to monitor progress. Alesandrini \& Larson (2002) view the role of the teacher to be very important in developing students' learning and comprehension ability. Clarke (1988) says that the responsibility of a reading teacher goes beyond presenting students with passages followed by comprehension questions. He suggests that the teacher must prepare reading tasks and reward them for trying as well as giving the right answer. Krashen and Terell (1983) also suggest that in reading instruction there should be intervention and for this they recommend the use of appropriate text.

The role of the students must be reciprocal too. Brindley, as in Nunan (2000) suggests that learner factors such as, learners' confidence, motivation, learning pace, proficiency in language skills, cultural knowledge are all important for effective teaching of reading. All these qualities have to be built up in the learners through teacher interaction. The more positive the teachers' attitude in all aspects regarding teaching the better he can motivate the learners/ students. Teachers attitude towards their profession have to be positive for the learning situation to be successful. As Wallace (1997) contends a professional has to have the qualities of scientific knowledge, time spent in rigorous study, a sense of serving the public, high standard of conduct, and the ability to perform demanding tasks in a competent manner. Problems in the field of education can be solved by adopting some new, effective course of action.

Researchers and educationists (Nuttal, 1996; Anderson et al., 1991; Barnett, 1989) have talked about several reading skills, namely: skimming, scanning, guessing, predicting, using inference, and carrying out receptive and reflective reading. Skimming involves glancing rapidly through a text to determine its gist. In this skill the reader narrows down his reading to attain general information, for example a date, number, place etc. Scanning on the other hand is reading to get specific information. It is detailed reading. Skimming and scanning are useful skills. They enable the reader to select texts which they would like to read. In receptive reading the student reads for comprehension. Guessing or prediction and inference are also used by the skillful reader to make reading effective. The teacher has to make students aware of these skills and encourage them to use these for effective reading.

Piaget $(1968,1971)$ the proponent of the Theory of Cognitive Constructivism claims that children develop certain cognitive abilities through their experiences. The teacher has to provide meaningful context and interesting things so that the students get the opportunity to actually engage in the experience of learning and get meaning from context. Bruner $(1960,1985)$ also had a significant contribution to the Theory of Constructivism. Bruner postulates learning as an active process in which learners build new ideas using prior knowledge and experience. Learners construct meaning and knowledge for themselves through their experiences. Bruner believed that learning was an active social process and students learnt new ideas based on the current experience and knowledge. The instructor should be there to guide and encourage the students. The Constructivists view the role of the teacher to be very important in developing students' learning.

Vygotsky (1987) has argued that students can learn better if they receive help from adults or children who are more advanced than them. The teacher can help the students learn by guiding them, giving 
them support and encouraging them. The teacher has to act as a facilitator, encourage and provide opportunities for group work. The role of teachers is very important in guiding and influencing students. According to Vygotsky, guidance and support from adults and peers helps students develop. This support that children need has been termed by Wood (2005, p. 99) as 'scaffolding'. Scaffolding by peers or adults helps a child to achieve a higher level of learning. However, though learning is mediated by others the teacher or the guide should know when to withdraw and let the child function independently in different contexts and situations outside the classroom (Cole, 1985; Edwards and Mercer, 1987).

Jerome Bruner $(1960,1985)$ also had a significant contribution to the theory of Constructivism. Bruner believed that learning was an active social process and students learnt new ideas based on the current experience and knowledge. The instructor should be there to guide and encourage the students. Thus the role of the teacher is crucial in developing students' learning. Teachers' attitudes towards teaching has to be supportive and facilitative for learning to be effective.

\section{Methods and Materials}

In order to understand the complexity of teacher attitudes it was essential to use a mixed methods approach (Creswell, 2009). Hence, this research was carried out using both qualitative and quantitative methods to obtain data to answer the research question. Triangulation of data, i.e. using both quantitative and qualitative methods to obtain data helped to explain more completely the variety and complexity of human behaviour (Cohen, et. al.; 2008).

The first step in the research procedure was to randomly select and contact 6 schools in Dhaka, Bangladesh to gain access to research participants. Due to institutional constraints, only 3 schools agreed to participate in the research. Table 1 shows the distribution of teachers and students who participated in this study. In total, 8 teachers and 100 students participated in this study.
Table 1: Distribution of research participants School

\begin{tabular}{|c|c|c|c|}
\hline School & Teachers & $\begin{array}{c}\text { Male } \\
\text { Students }\end{array}$ & $\begin{array}{c}\text { Female } \\
\text { Students }\end{array}$ \\
\hline Bangla Medium & 04 & 20 & 30 \\
\hline English Medium & 04 & 27 & 23 \\
\hline Total & 08 & 47 & 53 \\
\hline
\end{tabular}

The following methods and tools were used to collect data for this study:

1. Class observations

2. Questionnaires were given to both teachers and students.

3. The students also had to take a comprehension test.

4. Semi-structured interviews of teachers.

5. Focus group discussion with students.

Once access was gained it was necessary to talk to the teachers and build rapport with them. This was done to make observation easy for both the participants and the researcher. In studies which relate to behavioral sciences observation is the most commonly used accurate tool for research (Kothari, 1996). Permission was taken from the eight teachers to observe one reading class of Class IX and one of Class X taught by them. These class observations provided dual advantages of reliability and validity. Care was taken to observe the classes from an absolutely non-subjective, unbiased stand point. The researcher sat at the back of the classes quietly recording everything that the teachers and students did, systematically and accurately.

Different questionnaires were used for teachers and students, which were administered during recess after the observations took place. Before participants filled in the questionnaire, they were provided with an explanation about the objective of the study and use of the data. The aim of the questionnaire provided to teachers was to find out their attitude towards reading. Additionally, semi-structured interviews were conducted with all 8 participant teachers to obtain an in-depth understanding of their views regarding teaching of English reading comprehension. Students were administered a questionnaire that investigated their reading habits. Furthermore, focus group discussions were conducted to establish whether there was any relationship between the reading habits of the students and the teachers' practices of teaching reading. 
A further step used to elicit data regarding English reading comprehension ability was done through a comprehension test. The test required students to answer the questions based on the given passage. Texts provided to students of School 1 and School 2 were given from the prescribed textbook of Class IX and X, while students of School 3 were given a text from an old exam question paper. The aim of the comprehension test was to assess the reading and comprehension ability of students. They were given thirty five minutes i.e. one class period for taking the tests. The comprehension test for School 1 and 2 contained 2 passages. 5 questions were asked from each passage totaling a score of 10 points. In case of School 3, only 1 passage was used containing 5 questions of 2 points each totaling 10 points.

Data analysis consisted of using both quantitative and qualitative methods. Data from both teachers' and students' questionnaires and the comprehension test results were analysed quantitatively. Alternatively, interviews and FGDs were analysed using both deductive and inductive qualitative methods. Combination of these methods generated in-depth insights into teacher attitudes towards teaching of reading and students' reading proficiency.

\section{Results and Discussion}

Data collected in various categories were analysed to test teacher attitudes towards reading and their effect on students' reading proficiency. Class observations revealed the instructional methods used by the teachers and the tasks given by them to students. None of the participant teachers of the 3 schools conducted any pre-reading activity, rather in both School 1 and School 2 stress was given on reading aloud and pronunciation. Students were not given enough time to read for comprehension. In all three schools the text was partly explained by the teacher before allowing students time to comprehend the text. So, in answering questions students gave the view of teachers instead of answering from their own comprehension. None of the teachers in their schools prepared the students with any scaffolding. Observation revealed that teaching was teacher centered and students could not participate in the learning process. The teachers read the text aloud themselves and did not engage students in the reading activity which made reading an uninteresting exercise. As a result, this negative attitude of teachers towards reading does not promote students' reading proficiency.

According to Vygotsky (1987), teachers could help students through interaction but in these cases the teachers were more instructional than facilitating. Students should have the opportunity to practice language skills under the guidance of the teacher. Observation showed that reading was not taught as a skill adequately. Reading proficiency and reading comprehension does not only depend on language proficiency but also on the use of reading strategies or reading skills (Nuttal, 1996). This involves the readers guessing, categorizing information, and using prior knowledge to understand information. None of the techniques of reading were used or taught by the teachers. The analysis of the teachers' questionnaire also confirms that these same teachers do not follow the reading strategies nor did they use the CLT approach in class.

Seliger's (1972) research in reading has shown that there is a direct relationship between comprehension and speed of reading. As these are both equally important, reading specialists have shown that students who read slowly have poor comprehension (Carell et al, 1988). Slow readers often cannot grasp the meaning of a text. So in teaching reading, teachers along with developing students' reading skills also have to make them speed up their reading. But the method of teaching reading used by the teachers could not arouse the interest of the students in any way. As no scaffolding was provided by the teacher, students were busy with rote learning instead of developing and improving their English reading skills. The use of schema, culture and social context also become important factors in the learning process. The teachers have to guide and facilitate the schema of the students to make their reading easy and comprehensible. To encourage students reading habits, teachers themselves must read and show students that they value and enjoy reading themselves (Nuttal, 1996). In general, school teachers of Bangladesh do not have the reading culture. Since this cultural aspect is absent among teachers, they do not encourage it among their students. 
The teachers' questionnaires looked at their demographics, their work load and specifically their views regarding teaching of reading, motivation and attitude towards reading. Analysis of demographic data revealed that none of the participant teachers had any formal teacher education degree or any teacher training though their teaching experience was more than five years. The level of education, training and experience are crucial factors in providing quality education to learners. The teachers expressed that they were overworked as more than $60 \%$ of participant teachers had to take at least twenty classes per week, while around $38 \%$ took less than twenty but more than 15 classes a week. This meant that the workload of the teachers was excessive, indicating difficulty in executing their duties effectively.

The teachers' views and attitudes towards teaching reading comprehension are shown in Table 2a \& 2b. Teachers' regard reading necessary mostly for learning grammar (38\%), followed by vocabulary (25\%) and pronunciation (25\%), and least necessary for comprehension (13\%). Teachers' also expressed that when reading, students are most likely to face difficulty with pronunciation (50\%), followed by comprehension (25\%) with least difficulty in vocabulary $(13 \%)$ and grammar $(13 \%)$.

Table 2a: Teacher views towards teaching reading comprehension

\begin{tabular}{|c|c|c|c|c|c|c|c|}
\hline \multicolumn{4}{|c|}{ Reading necessary } & \multicolumn{4}{c|}{ Areas of reading difficulty } \\
\hline Comp. & Vocab. & Grammar & Pron. & Comp. & Vocab. & Grammar & Pron. \\
\hline $13 \%$ & $25 \%$ & $38 \%$ & $25 \%$ & $25 \%$ & $13 \%$ & $13 \%$ & $50 \%$ \\
\hline
\end{tabular}

Table 2b: Teacher views about reasons for reading

\begin{tabular}{|c|c|c|c|c|c|c|c|}
\hline \multicolumn{2}{|c|}{ Use of reading strategies } & \multicolumn{4}{|c|}{ What reading helps } & \multicolumn{2}{c|}{ Reading for pleasure } \\
\hline Yes & No & Comp. & Writing & Speaking & Listening & Yes & No \\
\hline $0 \%$ & $100 \%$ & $25 \%$ & $75 \%$ & $63 \%$ & $25 \%$ & $25 \%$ & $75 \%$ \\
\hline
\end{tabular}

With regard to teaching of reading the teachers' attitudes were also negative. They stressed the importance of reading aloud. In Table $2 \mathrm{~b}$ we see that none of the teachers used the reading strategies in class and they did not make their students use these either. Regarding the usefulness of reading, $75 \%$ of the teachers answered that reading was important for writing, $63 \%$ speaking and $25 \%$ each for listening and comprehension. Only $25 \%$ of the teachers, who were all from English medium schools regarded reading for pleasure as a good pastime.

Table 3: Student's response towards the importance and difficulty of reading English

\begin{tabular}{|c|c|c|c|c|c|c|}
\hline \multirow{2}{*}{$\begin{array}{c}\text { School } \\
\text { Category }\end{array}$} & \multicolumn{3}{|c|}{ Importance of Reading } & \multicolumn{3}{c|}{ Difficulty of Reading } \\
\cline { 2 - 7 } & Studies & Pleasure & Helps Comp. & Vocabulary & Grammar & Comp. \\
\hline English & $50 \%$ & $15 \%$ & $20 \%$ & $20 \%$ & $15 \%$ & $20 \%$ \\
\hline Bangla & $50 \%$ & $5 \%$ & $9 \%$ & $35 \%$ & $20 \%$ & $31 \%$ \\
\hline
\end{tabular}

Table 4: Students' response towards use of reading strategies and receiving teacher support for reading English

\begin{tabular}{|c|c|c|c|c|}
\hline \multirow{2}{*}{ School Category } & \multicolumn{2}{|c|}{ Use of reading strategies } & \multicolumn{2}{c|}{ Receiving teacher support } \\
\cline { 2 - 5 } & Yes & No & Yes & No \\
\hline English & $16 \%$ & $34 \%$ & $12 \%$ & $38 \%$ \\
\hline Bangla & $9 \%$ & $41 \%$ & $7 \%$ & $43 \%$ \\
\hline
\end{tabular}

The questionnaires for students elicited answer using more than one option. Results reveal information about their problems regarding reading. that the total number responses came to more than Table 3 shows the result of students' responses a hundred, as some students had marked multiple toward the importance and difficulty of reading areas of difficulty in reading English. Regarding English. Students were provided the opportunity to importance of reading, all students from both 
English and Bangla medium schools agreed that it was important for their studies. However, English medium students $(15 \%)$ were more likely to read English for pleasure than students of Bangla medium schools (5\%). English medium students (20\%) regard reading to be more important than Bangla medium students $(9 \%)$ to help increase comprehension. In case of difficulty of reading English, responses of English medium students show that they were less likely to face difficulty compared to Bangla medium student in terms of vocabulary, grammar and comprehension.

Table 4 provides an overview of students' responses to their use of reading strategies and support received from teachers. Students' responses suggest that most do not use any strategies for reading. However, English medium students (16\%) are more likely to use reading strategies for comprehension compared to Bangla medium students $(9 \%)$. In case of receiving teachers' support for improving reading comprehension, majority of students of both English and Bangla medium schools responded negatively.

The comprehension test was taken to test the students' ability to understand a text after reading it. Table 5 represents the average scores obtained by students in the comprehension test. The combined average score of students of School 1 and 2 (3.98) was lower than the average score of students of School 3 (4.8). The comprehension test results revealed that the reading proficiency of students was not too developed. This indicates that these students also need scaffolding and help with vocabulary and content to improve their reading proficiency. Students face lesser problems with a reading text and exercise if they are taught to practice the reading skills. The negative attitude of teachers was the cause of the poor reading proficiency of students. Though the students of School 3 scored higher than the students of School 1 and 2 their reading proficiency scores were also poor.

Table 5: Results of comprehension tests of students

\begin{tabular}{|c|c|c|c|}
\hline Schools & $\begin{array}{c}\text { Summation } \\
\text { of Scores }\end{array}$ & $\begin{array}{c}\text { No. of } \\
\text { Students }\end{array}$ & $\begin{array}{c}\text { Average } \\
\text { Score }\end{array}$ \\
\hline School 1 \& 2 & 199 & 50 & 3.98 \\
\hline School 3 & 240 & 50 & 4.8 \\
\hline
\end{tabular}

Semi-structured interviews were conducted with the participant teachers to assess their interest and attitude towards their students' reading habits. Interview results of all teachers showed that they were indifferent towards the reading habits of their students. They said that they never encouraged their students to read books outside the syllabus, nor were they interested in the readings done by students. Their responses confirm that they viewed passing exams as more important than spending time on extra reading. Teachers of School 3 answered that reading helped to develop comprehension and it was necessary to practice reading for comprehension. These teachers professed to reading newspapers and magazines but other than that they seldom did any reading. However, they said that they encouraged their students to read books.

The importance of reading as a separate skill was not emphasized by any of the teachers. They said that teaching reading was necessary for speaking; this naturally indicated that by reading they meant reading aloud and not comprehension. Teachers provided less importance to reading for comprehension compared to reading for passing examinations. The students are not taught any of the reading skills such skimming, scanning, guessing, inferring, and prediction (Anderson et al., 1991; Barnett, 1989). The teachers said that the students are made aware of these strategies at lower classes and at the secondary level they do not need to practice these, this makes it evident that teachers themselves are not aware of the necessity of using these strategies and skills. Reading problems that students face at the secondary school level are carried over from the elementary level of education.

Teachers are not aware of the new approaches and methods that can facilitate learning. This in turn depends on the fact that they do not receive any training, so they cannot incorporate the new methods in their classroom situations. Finally it was seen that job satisfaction and motivation were factors which teachers lacked. They had taken up teaching not because of the interest in the profession but because it was easily available and according to them an easy job to do. This reflects on the attitudes of teachers that they did not spend any time in planning lessons and preparing for lessons to be done in class. This 
indicates teachers' lack of commitment as a feature of their negative attitudes towards their profession. This negative and unprofessional attitude towards teaching cannot motivate students towards a better learning situation.

Focus group discussions (FGD) were held with students to find out their reading habits. Students were unanimous about the difficulty of reading English texts. Students of School 1 and 2 expressed that the primary reason for not reading English was the fact that they did not understand English books easily and this made it time consuming and uninteresting for them. They also expressed that they did not have any English books to read. The school libraries did not provide the students with any English reading materials. In School 3 the students said they preferred to read short articles and magazines more than books. Most students from School 3 expressed that they did not get enough time to read books outside those prescribed in their syllabus after finishing their academic studies. Students of all the schools also asserted that their teachers never encouraged them to read English books. Teachers approach towards reading is not facilitative so the students become reluctant to approach any reading material which they do not need to read. Their reading is limited to reading only for examinations and passing their exams. So there is no practice of reading and no improvement of reading proficiency. Therefore, incomprehensibility, lack of time, lack of materials was cited by students as reasons for not being good readers, becoming a vicious circle which goes on.

\section{Research gap and Conclusion}

The objective of this study was to examine the effect of teachers' attitudes on students' English reading proficiency. The rationale of conducting this research was that the results of National Board exams have shown that most of the failure of students occurs due to failure in English. Previous research has shown that educational failure occurs due to some kind of language failure. Research linking teachers' negative attitudes to students reading proficiency is a field that has not been studied in Bangladesh. The results of this investigation show that negative teacher attitudes are a primary reason for the lack of proficiency in English reading among students.
The role of the teacher is paramount in the classroom as Communicative Language Teaching (CLT) approach requires full involvement of teachers and students in the teaching learning situation. Teachers also need to create a situation of mutual respect that is conducive for creating a learning environment for students. Teachers' care and supportive behavior can have positive effect on students' learning. In teaching reading the teachers must pay special attention to giving background information, students' cultural background, prior knowledge and provide scaffolding as necessary. The teachers do not use any of the reading skills consciously and so they do not teach their students to use them either. The analytical mind of the students is not put to use as a result of which students do not know what to look for in a text. As reading skills are not taught and developed in them, they are unable to find out and understand the important parts of a reading text and grow as independent readers. This was proved by the result of the comprehension tests. Teachers should teach the students how to use and practice reading skills. Reading of extra material outside school textbooks should also be encouraged.

Teacher education and training is essential for professional development of teachers. Analysis of all the data confirms that negative attitude of teachers towards reading produces students with low levels of proficiency in reading English. Participant teachers did not have any formal degree on education, nor had they received any training. When teachers are indifferent, unprofessional and not motivated they cannot inspire a positive attitude towards any learning situation in the students. They should have scope to participate in workshops, seminars and all types of language developmental activities. This is an essential part of their professional development. It is only through training that teachers can be made aware of their role as facilitators. The training and re-training of teachers have to be a continual process. Training not only equips the teachers to handle the language skills but also makes them capable of handling classroom problems and challenges. Once the teachers are equipped with better methods of teaching reading and the other skills they can use these effectively with their students. Learning has to be made enjoyable and interactive. The 
teacher can do this by encouraging the students to participate actively in the learning process. Through training teacher attitudes can change as teachers can realize that their role is not authoritative but rather it is facilitative. In keeping with the contemporary methods of teaching the teacher can learn to become a guide and a facilitator. Thus, a continuing education programme for teachers should be introduced at the government level as this is too massive a task to be handled successfully by any private organization. The training of English teachers should concentrate on the teaching of reading and other skills. Once teachers gain adequate mastery over teaching the language skills, they will be able to transmit them effectively in the class room and produce proficient readers of English.

\section{References}

Alesandrini, K., and L. Larson. Teachers Bridge to Constructivism, The Cleaning House Publications, 2002.

Anderson, Neil J., et al. "An Exploratory Study into the Construct Validity of a Reading Comprehension Test: Triangulation of Data Sources." Language Testing, vol. 8, no. 1, 1991, pp. 41-66.

Barnett, Marva A. More Than Meets The Eye: Foreign Language Reading: Theory and Practice, Prentice-Hall, 1989.

Bruner, Jerome. "Vygotsky: A Historical and Conceptual Perspective." Culture, Communication and Cognition: Vygotskian Perspective, edited by James V. Wertsch, Cambridge University Press, 1985, pp. 21-34.

Bruner, Jerome S. The Process of Education, Harvard University Press, 1960.

Carrell, P.L., et al. Interactive Approaches to Second Language Reading, Cambridge University Press, 1988.

Clarke, Mark A. "The Shortcut Hypothesis of ESL Reading - or When Language Competence Interferes with Reading Performance." The Modern Language Journal, vol. 64, no. 2, 1980, pp. 203-209.

Cohen, Louis, et al. Research Methods in Education, Routledge, 2007.

Cole, Michael. "The Zone of Proximal Development:
Where Culture and Cognition Create Each Other." Culture, Communication and Cognition: A Vygotskian perspectives, edited by James V. Wertsch, Cambridge University Press, 1985, pp. 146-161.

Creswell, John W. Research Design. Qualitative, Quantitative, and Mixed Methods Approaches, Sage Publications, 2013.

Edwards, Derek, and Neil Mercer. Common Knowledge: The Development of Understanding, Routledge, 1987.

Ganie, Rohani, et al. "Reading Comprehension problems on English Texts Faced by High School Students in Medan." The 2nd Annual International Conference on Language and Literature, KnE Social Sciences, 2019, pp. 684-694.

Human Development Report (2017), Bangladesh.

Kothari, C.R. Reasearch Methodology: Methods and Techniques, New Age International, 2004.

Krashen, S.D., and Tracy D. Terrell. The Natural Approach: Language Acquisition in the Classroom, Alemany Press, 1983.

McArthur, Tom. Concise Oxford Companion to the English Language, Oxford University Press, 1998.

McKee, Steve. "Reading Comprehension, What We Know: A Review of Research 1995-2011." Language Testing in Asia, vol. 2, 2012.

Nunan, David. Designing Tasks for the Communicative Classroom, Cambridge University Press, 1989.

Nuttal, C. Teaching Reading Skills in a Foreign Language, The Bath Press, 1996.

Piaget, Jean. Psychology and Epistemology: Towards a Theory of Knowledge, Grossman, 1972.

Piaget, Jean. Six Psychological Studies, Random House, 1968.

Rahman, A. "Secondary English Education in Bangladesh: A Critical Review." Secondary School English Education in Asia: From Policy to Practice, edited by Spolsky, B., and Kiwan Sung, Routledge, 2015.

Seliger, H.W. "Improving Reading Speed and Comprehension in English as a Second Language”. ELT Journal, vol. XXVII, no. 1, 1972, pp. 48-55. 
Srivastava, R.N. Studies in Language and Linguistics, Kalinga Publications, 1995.

Stanovich, Keith E. "Toward an InteractiveCompensatory Model of Individual Differences in the Development of Reading Fluency." Reading Research Quarterly, vol. 16, no. 1, 1980, pp. 32-71.

Ur, Penny. A Course in Language Teaching: Practice and Theory, Cambridge University Press, 1991.
Vygotsky, L.S. "The Collected works of Vygotsky." Problems of General Psychology, Including the Volume Thinking and Speech, edited by Reiber, R.W. and A.S.Carton, Springer, 1987.

Wallace, Micheal J. and Tzong-Ho Bau. Training Foreign Language Teachers: A Reflective Approach, Cambridge University Press, 1991.

Wood, David. How Children Think and Learn, Blackwell Publishing, 1997.

\section{Author Details}

Dr. Zakia Ahmad, Associate Professor, Department of English, University of Asia Pacific, Dhaka, Bangladesh, Email ID: zakahmad17@gmail.com 